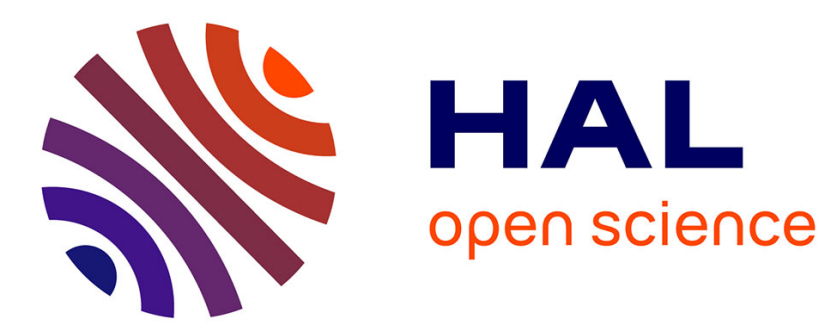

\title{
Pathology, assessment and treatment of structures affected by Delayed Ettringite Formation \\ Bruno Godart
}

\section{To cite this version:}

Bruno Godart. Pathology, assessment and treatment of structures affected by Delayed Ettringite Formation. Structural Engineering International, 2017, 27 (3), pp.362-369. 10.2749/101686617X14881932436771 . hal-01632429

\section{HAL Id: hal-01632429 \\ https://hal.science/hal-01632429}

Submitted on 10 Nov 2017

HAL is a multi-disciplinary open access archive for the deposit and dissemination of scientific research documents, whether they are published or not. The documents may come from teaching and research institutions in France or abroad, or from public or private research centers.
L'archive ouverte pluridisciplinaire HAL, est destinée au dépôt et à la diffusion de documents scientifiques de niveau recherche, publiés ou non, émanant des établissements d'enseignement et de recherche français ou étrangers, des laboratoires publics ou privés. 


\title{
Pathology, Assessment and Treatment of Structures Affected by Delayed Ettringite Formation
}

\author{
Bruno Godar, Université Paris-Est, IFSTTAR, Marne la Vallée, France. Contact: bruno.godart@ifsttar.fr
}

DOI: $10.2749 / 1335$

\begin{abstract}
Expansive internal sulphate reaction of concrete due to delayed ettringite formation (DEF) can damage concrete structures severely. DEF is defined as the formation of ettringite in a concrete after setting, and without any external sulphate supply but with water supply. This phenomenon occurs in concretes exposed to frequent humidity or contact with water, and subjected to a relatively high thermal treatment $\left(>65^{\circ} \mathrm{C}\right)$ or having reached high temperatures during casting. This reaction may cause large structural disorders due to unexpected deformations and additional stresses in concrete and reinforcement, and therefore knowledge about how to deal with such structures affected by DEF is essential. After a presentation of the disorders due to DEF and an analysis of their causes based on cases encountered in practice, the paper presents the three steps of the appraisal methodology by developing the assessment based on numerical modelling, and reviews the various treatment solutions that may be implemented to deal with existing affected structures whose serviceability and structural safety may constitute a serious concern.
\end{abstract}

Keywords: concrete structure; delayed ettringite formation; disorder; appraisal; treatment.

\section{Introduction}

The expansive internal sulphate reaction due to delayed ettringite formation (DEF) can damage concrete structures severely. In healthy concretes, the primary ettringite (a hydrous calcium trisulphoaluminate) is a normal reaction product formed from the reaction of $\mathrm{C} 3 \mathrm{~A}$ and C4AF with gypsum during the plastic stage of the hydration of Portland cement. But, when temperatures in concrete are above $\sim 65^{\circ} \mathrm{C}$ during construction, the sulphates may be incorporated in other cement phases. After concrete hardening, very slow formation of higher volume secondary ettringite may occur as the water is incorporated in the ettringite crystal structure which can lead to potentially disruptive expansions. ${ }^{1}$ DEF is therefore defined as the formation of ettringite in concrete after setting, and without any external sulphate supply, but with a water supply. DEF appears in concretes exposed to water or to frequent humidity (at least over 90 to

Peer-reviewed by international experts and accepted for publication by SEI Editorial Board

Paper received: July 20, 2016

Paper accepted: November 28, 2016
$95 \%$ relative humidity), and subjected to a relatively high thermal treatment $\left(>65^{\circ} \mathrm{C}\right)$ or having reached equivalent temperatures for other reasons (massive cast-in-place concrete, concrete casting during summer, etc).

The expansive process leads to macroscopic local effects similar to those created by alkali-aggregate reaction (AAR) and mainly consisting of material swelling and micro-cracking and reduction of the mechanical properties which may cause large structural disorders due to unexpected deformations and additional stresses in concrete and reinforcement. The micro-cracking is principally present at the interfaces between the aggregates and the cement paste and is also disseminated in the cement paste. These microcracks whose size is around 10-20 microns are filled with a compact ettringite. The ettringite that is generally observed in the concrete has a wide range of textures, but it is mainly poorly crystallised and massive. ${ }^{1}$

The swelling of the material may cause large structural disorders due to unexpected deformations and additional stresses in concrete and reinforcement, and the problem is therefore to know how to deal with such structures affected by DEF. After a brief review of some cases encountered abroad and in France, and a presentation of the disorders due to DEF with an analysis of their causes, the paper presents the three steps of the assessment methodology and develops the assessment based on numerical modelling; then, it reviews the various treatment solutions that may be implemented to deal with existing affected structures whose serviceability and structural safety may constitute a serious concern.

\section{Brief Review of Some Cases Encountered}

The first reported cases of DEF occurred in some precast concrete elements subjected to heat treatment unsuited to the composition and environment of the concrete. The main examples of DEF world-wide include railway sleepers, ${ }^{2-9}$ and massive castin-place concrete components. ${ }^{10-13}$

In France, the first case of DEF was observed in 1997 in a cap beam resting on two circular columns and supporting the deck of the Ondes Bridge. ${ }^{14}$ Then other bridges with DEF were discovered; the bridge parts damaged by DEF were primarily massive structural elements (piers, cap beams on piers or abutments, etc.) in contact with water or subjected to high moisture. A brief description of these bridges may be found in Ref. [15] and a more detailed description is presented in Ref. [16].

More recently, DEF was discovered in some precast and prestressed concrete beams of about 25 bridges in France. These bridges were built around the year 1995, and DEF occurred only in the edge beams that are particularly exposed to high humidity (rain). The cracking on the external face of the edge beams is mainly longitudinal and relatively important, particularly at the ends. Cracking on the internal face of the edge beams is much less important, and all internal beams are free of cracks. The investigations conducted on these bridges showed that the damaged precast beams were 
subjected to a severe heat treatment during their fabrication.

\section{Presentation of Disorders}

The structures damaged by DEF in France are mostly civil engineering works, while buildings appear, at first glance, to be affected only slightly. This reaction is mainly found in bridges and in some dams. So far, most of the bridges damaged by DEF were built after 1980 and before the adoption of preventive measures in $2007 .^{17,18}$

The disorders presented are similar to those observed on structures damaged by AAR, except for pop-outs and exudation of gel. ${ }^{19}$ It shows that map cracking is the most frequent disorder observed on the faces of structures affected by DEF. Cracking is generally anarchic and can take the form of a crazing with small mesh size (20$50 \mathrm{~mm}$ ) and a rather small crack depth (20 to $50 \mathrm{~mm}$ ), or take the shape of a larger crack network (300 to $400 \mathrm{~mm}$ size) with greater crack depth (greater than $100 \mathrm{~mm}$ ) (Fig. 1). The crack opening is variable in each observed zone according to the evolution rate of the reaction. It can be a few tenths of millimetres for a crazing, and can reach several millimetres for a wide mesh cracking. The crack depth also varies with the degree of evolution of the disorders: cracking may be superficial (a few centimetres deep) or can propagate in depth, for a through cracking.

In some structures, map cracking leaves room for an oriented cracking. This happens in the case of a structural element where there is compression stress in a predominant direction, and the cracks open in the direction perpendicular to the main compression axis. This is particularly the case when horizontal cracks develop in prestressed precast concrete beams (Fig. 2), or when vertical cracks occur in columns or piers.

The expansion of the structure is generally associated with a change in the mechanical properties of the concrete material resulting from the formation of micro-cracks inside the material. In DEF cases, at the beginning of expansion (say, 0.2-0.3\%), micro-cracking first reduces the tension strength of concrete and its Young modulus. Then, significant reductions in compressive strength can be found for

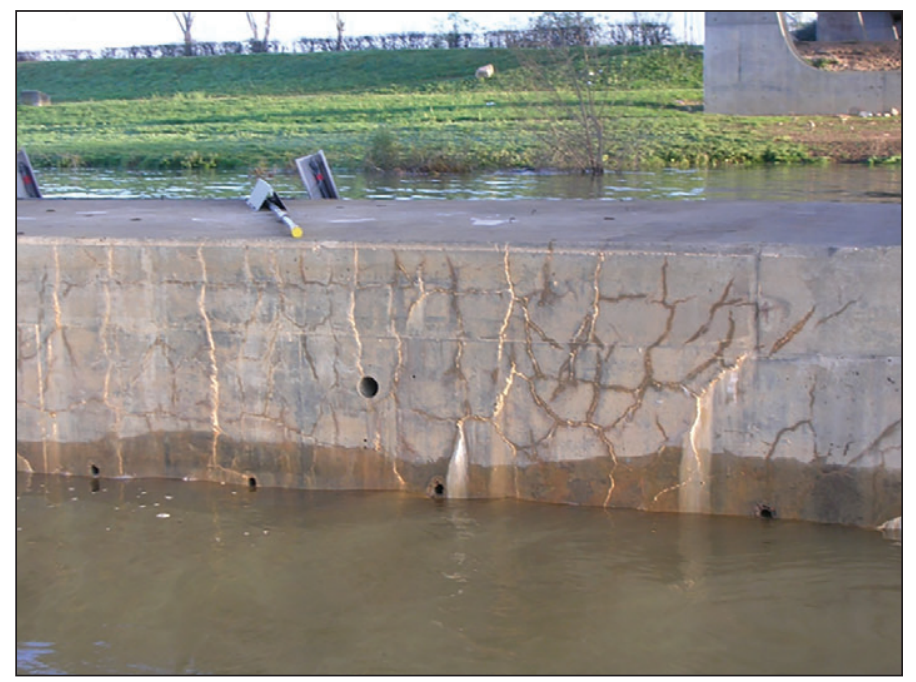

Fig. 1: Cracking of the base of a pylon (Bourgogne bridge: crack width $>0.3 \mathrm{~mm}$ )

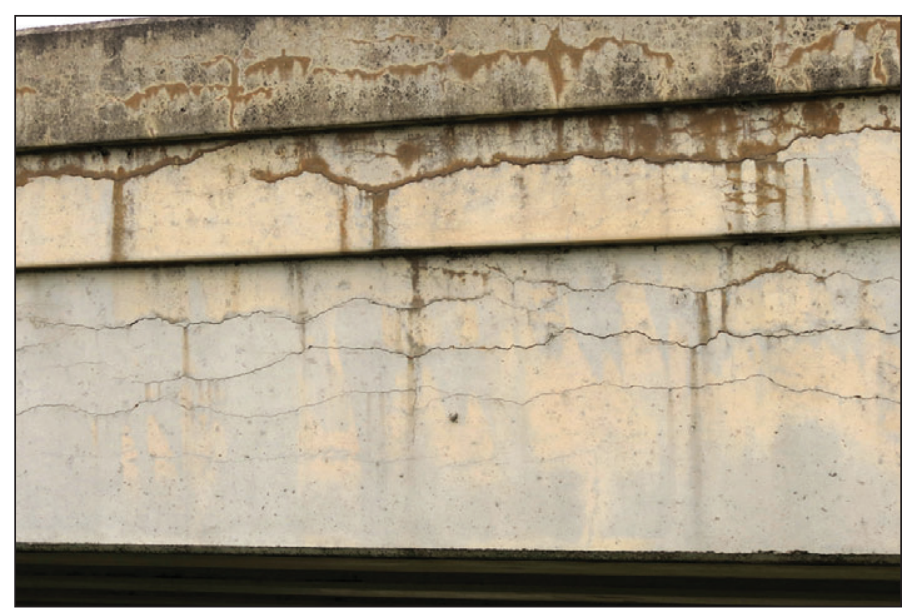

Fig. 2: Longitudinal cracks in the middle of a prestressed precast concrete beam

high and very high expansion levels (e.g. an expansion of $1 \%) .{ }^{20}$

The swelling of the material leads to significant internal stresses within the structure that are superimposed on existing constraints, and causes overstress in the reinforcing and prestressing steels. This leads to an expansion of the structure, as well as formation of cracks that occur when the stress state resulting from permanent loads, live loads and swelling of the material exceeds the tensile strength of the concrete. It is thus possible to observe cracks in theoretically compression areas, and there is usually a network of cracks that are more open on the bridge facings. This latter observation is probably due to differential swelling between the surface and the centre of the structure. The most credible assumption is that the centre expands more than the surface, because the temperature at construction is higher in the centre than at the surface and also because gradients of moisture exist within the concrete elements. Other factors such as a decrease in $\mathrm{pH}$ caused by carbonation of the surface concrete and leaching of surface alkalis also have to be considered.

\section{Causes of Disorders}

In Ref. [16], a comparative study was done of the factors that could be encountered in several investigated bridges. Table 1 is a synthesis extracted from this report, and shows some common features of the investigated bridges that were damaged by DEF: a massive structure, exposure to water or rain, casting in summer, a maximum temperature inside concrete above $75^{\circ} \mathrm{C}$ (except for one) inside the concrete, a high cement content (above $380 \mathrm{~kg} / \mathrm{m}^{3}$ ) and a rather high content in sulphates (above $2.5 \%$ of $\mathrm{SO}_{3}$ ) and aluminates (above $7 \%$ of $\mathrm{C} 3 \mathrm{~A}$ ).

There are several reasons that explain the occurrence of these disorders. Among them are the popular trend to increase the performance of concrete, 


\begin{tabular}{|c|c|c|c|c|c|c|}
\hline Bridge name & Ondes & Bourgogne & Lodève & Bellevue & Beynost & Cheviré \\
\hline Date of construction & 1955 & 1990 & 1980 & 1988 & 1982 & $1988 / 1989$ \\
\hline Casting of concrete & August & $\begin{array}{c}\text { August/ } \\
\text { September }\end{array}$ & $\begin{array}{c}\text { August/ } \\
\text { September }\end{array}$ & $\begin{array}{c}\text { August/ } \\
\text { September }\end{array}$ & August & July/August \\
\hline Structural part & Cap beam & Base of pylon & Cap beam & Pier & Cap beam & Base of pier \\
\hline $\begin{array}{l}\text { Delay in occurrence of } \\
\text { damage (years) }\end{array}$ & 27 & 6 & 9 & 10 & 10 & 8 \\
\hline Environment & $\begin{array}{c}\text { Water-proofing } \\
\text { problem }\end{array}$ & $\begin{array}{c}\text { Immersed and } \\
\text { variable } \\
\text { immersion }\end{array}$ & $\begin{array}{c}\text { Lack of } \\
\text { drainage }\end{array}$ & $\begin{array}{c}\text { Immersed and } \\
\text { variable } \\
\text { immersion }\end{array}$ & $\begin{array}{l}\text { Exposure to } \\
\text { rains }\end{array}$ & $\begin{array}{l}\text { Rains and } \\
\text { capillarity }\end{array}$ \\
\hline$T \max \left({ }^{\circ} \mathbf{C}\right)$ & 80 & 79 & 80 & 80 & 69 & 75 \\
\hline W/C ratio & 0.50 & 0.45 & 0.47 & 0.54 & 0.49 & 0.48 \\
\hline Nature of cement & CEM I & CEM I & CEM I & CEM II/A & CEM I & CEM II/A \\
\hline Cement content $\left(\mathrm{kg} / \mathrm{m}^{3}\right)$ & 430 & 400 & 400 & 380 & 350 & 385 \\
\hline $\mathrm{SO}_{3}$ content $(\%)$ & 2.5 & 2.8 & 2.6 & 2.5 & 3.4 & 2.5 \\
\hline C3A content $(\%)$ & 11.2 & 8.2 & 9.8 & 7.0 & 10.4 & 7.0 \\
\hline
\end{tabular}

Table 1: Comparative study of factors encountered in some investigated bridges

with the development of (very) high performance concrete, and the tendency to increase the speed of erection of structures. Another additional reason is the increase in the size of the structural elements permitted by heavier manufacturing equipments and audacious designs. This has led to the development of high-performance cement resulting in an increase in the hydration heat. Consequently when some basic rules to control the heat release in structures are neglected, the temperature inside the structural elements may exceed the thresholds and leads to DEF.

An analysis of the bridges affected by DEF shows that the structures or parts of structures in constant contact with water or wet soils, and parts constantly sprayed with water (e.g. due to a leakage of expansion joints) are the most damaged. This analysis confirms the key role played by water in the development of this pathology.

Until now, it was admitted that structural parts exposed to humidity should be subjected to an internal relative humidity of $90-95 \%$ to show distress. A recent experimental study conducted at IFSTTAR ${ }^{21}$ on cylinders with $110 \mathrm{~mm}$ diameter and $220 \mathrm{~mm}$ height concluded that specimens immersed in water as well as specimens stored at $100 \%$ relative humidity (RH) develop an expansion very quickly (maximal expansion 1.4 $\%)$, specimens stored at $98 \% \mathrm{RH}$ show an expansion after a long period (600 days), and specimens stored at 96, 94 and 91\% RH do not expand. Based on this study, it appears that the threshold of internal humidity to develop expansion is around 98\% $\mathrm{RH}$, and that it is influenced by the leaching of alkalis on the surface.

\section{Some Other Considerations Related to DEF}

A research conducted in France ${ }^{21}$ showed that a concrete specimen exposed initially to a relative humidity of $90 \%$ without expansion, and then to an immersion, expands at the same rate had it been immersed since the beginning; this means that the expansion potential is latent in a structure and that any unfavourable change in the exposure condition can trigger the reaction.

Another critical problem may arise due to this potential latent DEF expansion in a structure: a study conducted at IFSTTAR ${ }^{22}$ confirmed that concrete specimen subjected to different thermal scenario after 100 days of maturation, showed the risk of a significant expansion associated with DEF for a late heat treatment on concrete. Moreover, a pessimum effect with the heating duration has also been highlighted. Therefore, structures heat-cured after certain storage duration, or exposed to a second heat treatment, can develop a significant expansion, and this should be carefully considered, e.g. in the case of radioactive waste concrete containers.

However, it is reassuring for those involved in construction that the survey of the 25 bridges damaged by
DEF in France shows a great many of them presenting a slowdown in the evolution of cracks 10 years after their occurrence, while in only four bridges cracking is shown to continue to be growing.

\section{Assessment of Structures}

\section{Three Steps of the Assessment Methodology}

Once the presence of significant DEF in the concrete has been established on samples taken from the structure with the help of laboratory investigations-among them the most valuable is the scanning electronic microscopy examination-the next action is to analyse the implications of the problem as regards the overall safety and the management of the structure. Following the methodology developed in Ref. [23] for AAR, the assessment of structures affected by DEF may be broken down into three steps: the initial appraisal, the consideration of severity of reaction and the structural assessment.

The first step of appraisal begins with a review of the available documentation on the design and construction of the structure (inspection records, any modifications and/or repair measures). The extent to which configuration of reinforcement and prestress contains expansion in all three directions determines the vulnerability of the structure to DEF, so detailed reinforcement drawings and prestressing tendon schematics are paramount. The appraisal continues with site investigations such as the 
measurement of the cracking index to estimate expansion, the measurement of global deformation of structures with time and the determination of the moisture levels in the concrete. Then this appraisal proceeds with laboratory investigations: various mechanical testing and residual expansion testing on cores (like the one developed by $\mathrm{LCPC}^{24}$ ) for estimating the potential magnitude of future concrete expansion.

In the second step, the qualitative assessment of the reaction severity is done by crossing site investigations (e.g. number of cracks, expansion, water availability) with laboratory investigations (e.g. microscopy results, mechanical reduction, core expansion). According to Ref. [23], this second step may be implemented by distributing the structures among the four classes of severity defined by LL, LH, HL and HH (see Table 2), assuming that the structural elements are well reinforced and there are no other structural or deterioration concerns. In order to move towards a quantitative assessment, some precise advices may be given where the results of the laboratory and site investigations have to be considered as low or high. In terms of site investigations, it may be considered that a part of a reinforced concrete structure having a cracking index above 1 or $2 \mathrm{~mm} / \mathrm{m}$ or a single crack greater than $0.5 \mathrm{~mm}$ is classified as high; concerning the water availability, an immersion in water of a part of a structure has to be considered as a more aggravating factor than an exposure of the same part to alternative rain and drying conditions which is in itself more detrimental than an exposure to a humid environment. In terms of laboratory investigations, a severe microcracking of the observed samples under a microscope, or a reduction of $5-10 \%$ of the compressive strength of the concrete, or a residual expansion of concrete (measured according to Ref. [24]) greater than $0.05 \%$ has to be considered as high.
In the LL class are found structures where the diagnosed DEF is too little to cause significant damage in the structure. In this case, it is advised to practise the regular inspection regime of the structure in order to detect an eventual development of cracking that could merit a reassessment.

In the LH class, two cases are possible: either the sampling programme may have missed the locations of the severe disorders found in the in situ investigation, or the disorders observed during on-site investigation could have other causes. In both cases, a new investigation program is required. As the in situ inspection did find major deterioration features, monitoring on the evolution of the structural disorders is strongly advised.

In the HL class, either DEF is only a localised problem in the sampled part of the structure, or the laboratory results show the early stages of DEF which have yet to develop significant disorders in the structure. In this case, additional awareness during the regular inspection regime of the structure has to be applied in order to detect the development of cracking that could trigger a reassessment.

In the $\mathrm{HH}$ class, structures are clearly affected by DEF. Monitoring of the structures alone is not enough anymore and a structural assessment to identify vulnerable details is strongly advised, as well as an investigation program to predict the future development of the DEF.

The third and last step of the methodology is devoted to structural assessment and is applied to critical elements of the structures classified in the highest reaction severity class HH. Its objective is to identify significant current and future serviceability and safety issues that have an impact on the function of a structure. This structural assessment comprises a "structural severity rating" of each structural element and detailed assessment of those critical elements identified and the overall behaviour of the

\begin{tabular}{|l|c|c|c|}
\hline \multirow{2}{*}{\multicolumn{2}{|c|}{}} & \multicolumn{2}{c|}{$\begin{array}{c}\text { Site investigation (\# cracks, } \\
\text { expansion, water availability) }\end{array}$} \\
\cline { 3 - 4 } & & Low & High \\
\hline \multirow{2}{*}{$\begin{array}{l}\text { Laboratory investigation (microscopy results, } \\
\text { mechanical reduction, core expansion) }\end{array}$} & Low & LL & LH \\
\cline { 2 - 4 } & High & HL & HH \\
\hline
\end{tabular}

Table 2: Summary of reaction severity assessment based on site and laboratory investigations (from Ref. [23]). structure. The following section emphasises on the full structural analysis based on numerical modelling.

\section{Structural Assessment Based on Numerical Modelling}

The structural analysis of critical elements is mainly based on a calculation involving inevitably a numerical modelling that can also be used to analyse the global behaviour of a structure. In this analysis, the consequences of a local failure of part of the structure need to be considered. Numerical modelling can also provide a long-term management tool and allows evaluation of possible strengthening and moisture mitigation techniques.

Modelling DEF involves real structures with complex geometries and details, mechanical aspects such as the initial stress state due to loading conditions, shrinkage and creep, physical processes including temperature and moisture effects, chemical reaction rates causing swelling, and other degradation mechanisms that may also be present in the structure. As in the case of AAR, the best model is based on a finite element method (FEM) and considers thermo-hydro-chemo-mechanical couplings. To complicate things further, the determination of the model parameters requires extensive and longterm experimental tests. Due to this complexity, any simulation model should be calibrated based on the monitoring data and pertinent information obtained from in situ and laboratory investigation of the structure investigated.

One of the first comprehensive models used to assess DEF-affected concrete structures has been developed at IFSTTAR. Following the theoretical developments proposed in Ref. [25], the total deformation of concrete is the summation of the elastic deformation, the plastic deformation, the deformation due to shrinkage and creep and the chemical-induced deformation. The chemically induced part of the deformation is derived from Larive's law $^{26}$ successively improved in Ref. [27] and is based on Eq. (1). In this equation, $\varepsilon_{\infty}$ corresponds to the final expansion, $\tau_{\mathrm{c}}$ and $\tau_{1}$ are the characteristic and the latency times, respectively (corresponding to the swelling rate and the duration before the onset of expansion), $\varphi \otimes 1 \delta$ are two complementary parameters introduced by Ref. [27] into Larive's law to 
model an asymptotically linear phase at the end of the reaction which seems to be more relevant for DEF (Fig. 3).

$$
\begin{aligned}
& \varepsilon(t)=\varepsilon_{\infty} \cdot \frac{1-e^{-\frac{t}{\tau_{C}}}}{1-e^{-\frac{\left(t-\tau_{L}\right)}{\tau_{C}}}} \\
&\left\{\begin{array}{ll}
1 & \text { for AAR } \\
1-\frac{\phi}{\delta+t} & \text { for DEF }
\end{array}\right\} \\
& \text { with } 0 \leq \phi \leq \delta
\end{aligned}
$$

This model can then be implemented in FEM software (RGIB module). The chemo-mechanical computation is based on the results of two complementary modelling: one aimed at assessing the temperature field in the structure, and the other one consisting in solving the transient non-linear moisture-diffusion equation governing the evolution of humidity in the porous network of the structure. Fitting of Brunetaud's law is based on experimental data such as the results of the residual expansion test on concrete cores extracted from the structure and the results of the cracking measurement and the global deformation monitoring of the structure. Figure 4 shows an example of a fitting with the result of a residual expansion test applied on a core extracted from the bridge pier presented thereafter. Once the expansion law of the concrete has been calibrated, the calculation is conducted and its result validated with the value of a cracking index measured on the pier (Fig. 5).

The chemo-mechanical model shall also take into consideration the consequences of the stiffness reduction of the concrete by introducing a damage coefficient, and the effect of anisotropy; this latter effect has two origins, one linked to the casting direction of concrete in the structure, and the other resulting from the restrained expansion by the stress state.

After calculation, the model is able to give displacements, strains and stresses at every point of the structure. It is therefore possible to check if the ultimate and service limit states are attained or not, keeping in mind that uncertainties in both loads and resistance parameters remain a difficulty for developing a suitable safety format in the context of applying a non-linear FEM analysis for the assessment of existing structures. The model has beneficial aspects that also check whether some bars have yielded,

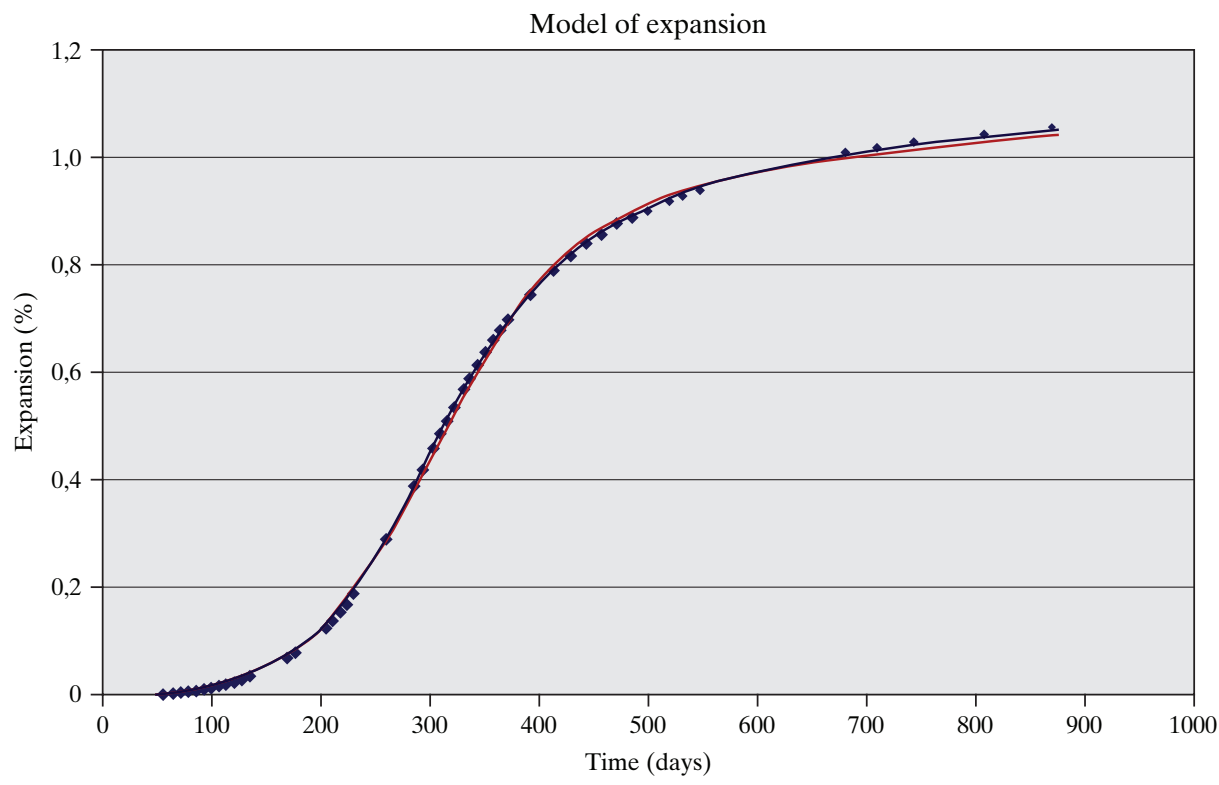

Fig. 3: Fitting of the Brunetaud's law (pink) with experimental points (blue diamonds)

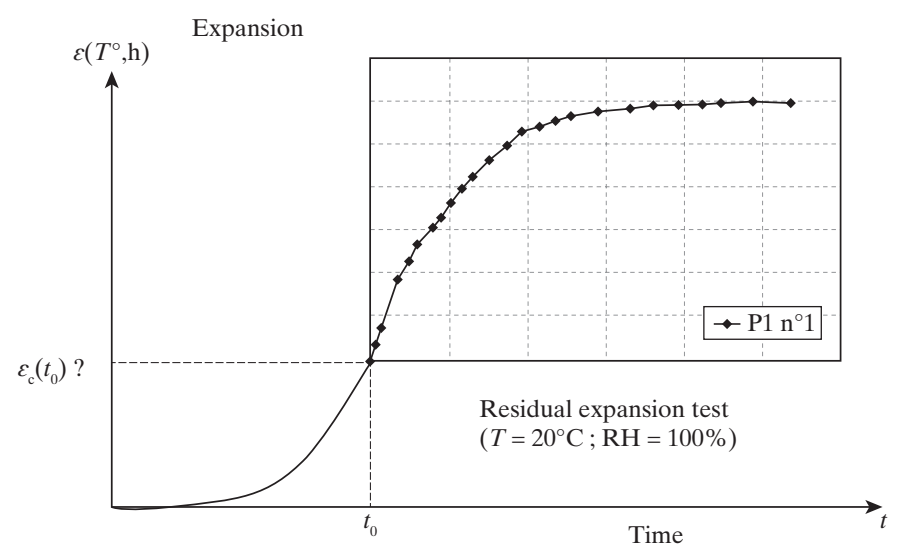

Fig. 4: Fitting of the Brunetaud's law with the result of an expansion test

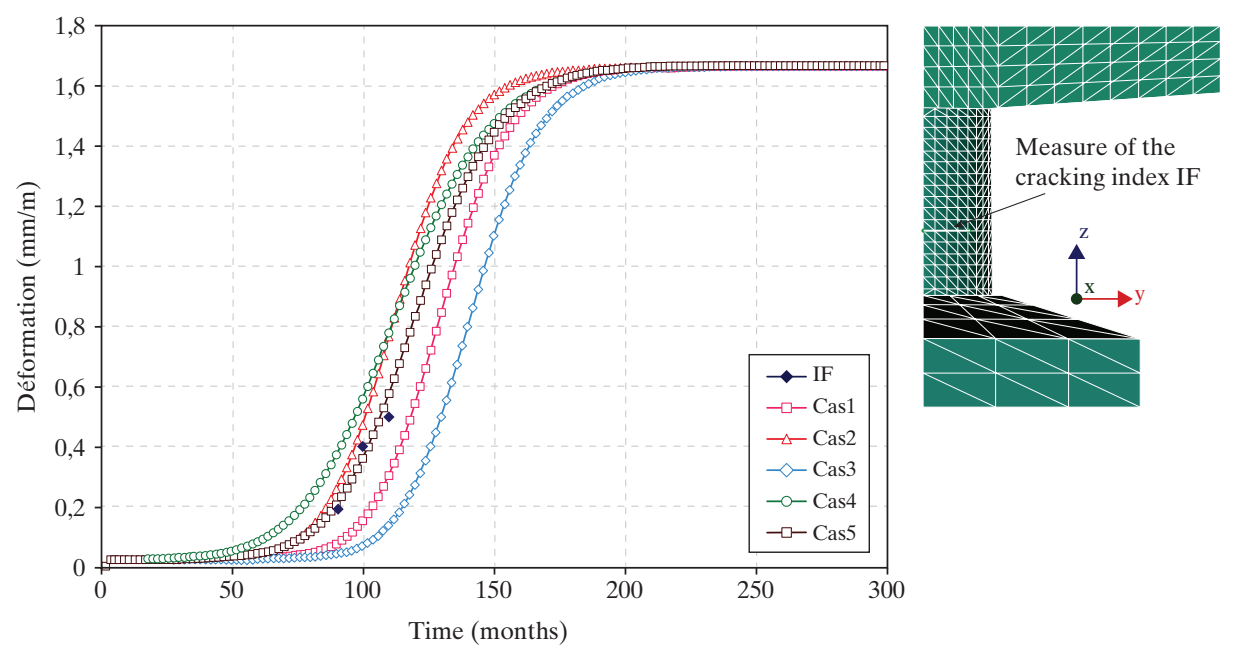

Fig. 5: Fitting of the model with the result of the measurement of a cracking index IF on the pier (blue diamonds) - the curve "Cas5" appears to be the best fitted curve

whether cracking is developing, whether concrete is able to sustain compression, and so on as shown in the Ref. [28] which presents the calculation results of a massive bridge pier and a precast prestressed concrete beam. Once the FEM calculation has been validated by comparison with the actual behaviour of the structure, it is then possible to predict the future evolution of the structure and to decide on treatment solutions. 

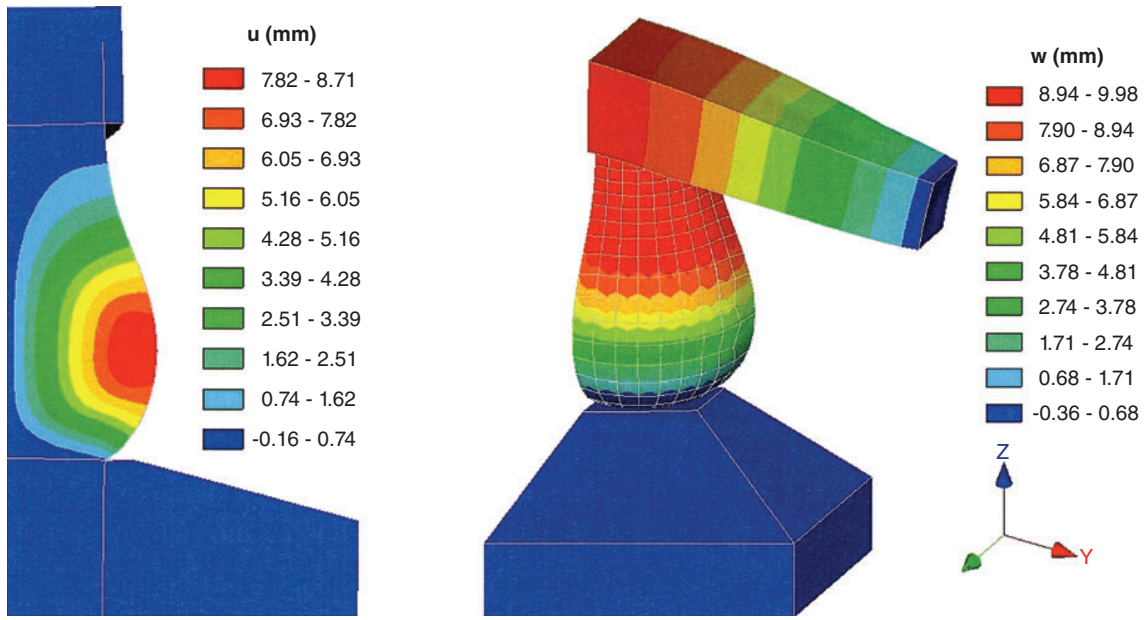

Fig. 6: ISO values of radial $(u)$ and vertical $(w)$ displacements of a pier column

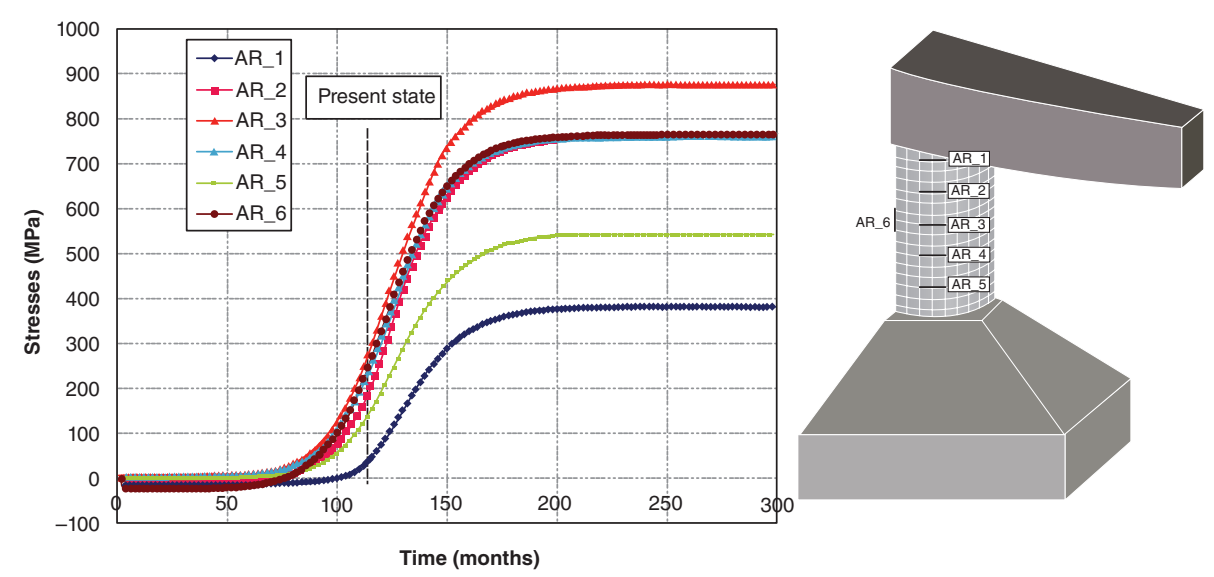

Fig. 7: Evolution of the calculated stresses in the reinforced steel bars of the pier column

To illustrate the results of such a calculation, Figs. 6 and 7 show, respectively, the expansion of a pier column and the computed stresses in the steel reinforcement of this pier column. In order to understand Fig. 6, it should be considered that the column is restrained at the bottom by the footing and at the top by the crossbeam that are both non-affected by DEF, and that the downward deflection of the crossbeam is due to the dead and live loads of the deck resting at the end of the crossbeam. The maximum vertical displacement at the top of the column reaches a maximum value of about $10 \mathrm{~mm}$, while the transversal displacements reach $9 \mathrm{~mm}$. The transversal swelling is more significant in the lower part of the pier where the saturation degree is higher (immersion of the footing and the bottom of the column in the river). These results highlight the relationship between expansion and water content in the concrete structure.

Figure 7 shows that, after a latency period, the swelling of the structure causes tensions in the steel bars which become quite important in the case of vertical (AR_6) and circular (AR_3, AR_4 and AR_5) bars, where the swelling is greater. The values of the tensile tresses in these reinforcing steel bars exceed $800 \mathrm{MPa}$ for the final expansion, whereas they do not exceed $330 \mathrm{MPa}$ in AR_1 and $500 \mathrm{MPa}$ in AR_2 (Fig. 7). In these calculations, a purely elastic behaviour of steel bars has been assumed; however, in reality, stresses over $500 \mathrm{MPa}$ cannot develop in the reininterpreted as an incursion of steel in the field of plasticity. The most important point is that the tensile stresses in the reinforcing steel bars will probably exceed the yielding threshold after about 3 years.

\section{Treatment Solutions}

Despite the fact that experiments of treatment are still extremely rare in the case of DEF-affected structures, some conclusions may be drawn from the few bridges damaged by DEF in France and from some laboratory tests. $^{29}$ These treatment solutions may forcement and the results have to be be designed for protecting users, third parties or structural elements, delaying the beginning of a reaction or slowing down its growth, reducing the mechanical consequences of the pathology, and rehabilitating the structure when the reaction is completed.

\section{Protection of Users, Third Parties or Structural Elements}

The main solutions to protect third parties and users from falling concrete blocks are the prohibition of access to dangerous zones, the removal of loose blocks and scales, and the installation of protection nets.

For structural elements exposed to shock in tidal zones, a mechanical protection against erosion may be done by surrounding the element with concrete shells. These shells may be either disconnected from the element to allow its free expansion, or bound to the element in order to bring a confinement effect to oppose the residual expansion.

\section{Mitigation of the Reaction}

The main actions to mitigate the DEF are to limit water penetration into the concrete and to avoid contact with water. Different solutions with various efficiencies exist.

Injection and bridging of cracks are generally ineffective remedies which do not act on the reaction and do not produce noticeable improvement in the concrete strength to resist the development of cracking. This technique simply prevents water from penetrating inside the cracks, provided that the product injected or used for bridging is sufficiently flexible to follow the likely future opening of the cracks.

The application of paint on structures constitutes the simplest method to implement coatings. The painting layer has a small thickness (maximum 200-300 microns), and its efficiency is rather low and even null in the case of totally immersed structures, as proved in laboratory experiments. ${ }^{29}$

The application of a watertight coating having generally a significant thickness (a few millimetres) may act against the reaction while trying to reduce the penetration of water in the structure. It is a provisional solution that allows a possible extension of the lifespan of the structures. 
Finally, the drainage of water, the water collection, the renewal of a deteriorated waterproofing membrane, and the sealing of joints between elements are always beneficial to mitigate the reaction.

\section{Mechanical Limitation of Expansion}

Different methods of mechanical treatment exist: addition of reinforcing steels or composites when the objective is a simple strengthening, confinement with a high compression when the aim is a remarkable reduction of the expansion, the release of stresses, and the separation of swelling elements from non-swelling elements in the structure.

Fixing the amount of compression to be added to structures to fight against expansion is a real challenge. Based on previous cases of structures affected by AAR, the amount of additional compression stress to be introduced by prestressing is in the range of 5-10 MPa, and sometimes more. Considering that in expansion tests conducted in the laboratory, the free expansion of specimens affected by DEF is five to ten times higher than the free expansion of specimens affected by AAR, it can be deduced that the level of compression stresses should be rather high. But sufficient experience in this domain is not available, and it is paramount to take into account the exposure condition of the structure and the residual potential swelling of the concrete.

Among the existing techniques, it is thus possible to insert, to enclose, or to hoop elements of structures with reinforcement or prestressing tendons and bars. These strengthening units are primarily made of steel, but the use of composite materials is increasing. Mechanical "restraining" has no effect in the untreated directions; it has a short-term effectiveness which is not always systematic, and a longterm effectiveness which is not proved. If a "restraining" is considered for treatment, then a threedimensional active strengthening (with prestress) is recommended.

Another type of active treatment consists in releasing the constraints by sawing whole or part of the structure. This operation is often applied with success on gravity dams affected by AAR, and there is no reason why this type of action would not be effective in the case of DEF. But if DEF seems to be leading to much more expansion than AAR, the stress release could have a short-term effectiveness, and will presumably require repeating the operation insofar as it does not oppose the progress of the reaction.

\section{Other Solutions}

The demolition and then the replacement of a structure is sometimes an inevitable but expensive solution. It has been proposed in the case of the structure presented in Fig. 1 (reconstruction of the base of the pylon of the Bourgogne bridge), but facing the technical difficulty, the risk arising during the load transfer and the high costs of this replacement, this solution was abandoned in favour of a solution for extending the life of the affected structure. The expensive and traumatic aspects of a complete demolition can be attenuated by the realisation of a partial demolition followed by a rebuilding.

Finally, it should also be mentioned that monitoring may be a solution to manage the risks due to DEF or to give more time to take a decision concerning the future of the structure while ensuring its safety of use.

\section{Conclusions}

DEF may be considered as a relatively new reaction to degradation of concrete. Presently, only some countries appear to be affected by DEF cases; it is probable that new DEF cases will be discovered in already affected countries and in other countries not yet affected.

Designers and owners of structures must be aware of this possible pathology. Massive parts and precast products are most vulnerable to this reaction, depending on the temperature reached in the concrete during the setting and on the conditions of exposure. The main challenge for the owners is therefore to know how to deal with these structures.

After a presentation of the disorders and their causes, an assessment procedure inspired by the appraisal methods developed for structures damaged by AAR has been proposed in this paper. It comprises three steps. The initial step reviews the available documentation on the design and construction of the structure. The second step is a combination of material and structural approaches with the objective to distribute the stock of structures into four severity classes. The third step is for structures in the highest severity class and consists of a structural assessment based on a non-linear FE analysis and a fitting of the expansion model with measures implemented on the structure. It helps to check the conditions of a structure affected by DEF in terms of safety, serviceability and durability limit states. An example of application on a pier of a bridge shows that the determination of the mechanical condition of the structure is predominantly governed by the variation of stresses in the different reinforcing steels.

Then, various treatment solutions are presented and discussed. They are classified according to their purpose: to protect users, third parties or structural elements, to mitigate the reaction, to limit the expansion by mechanical means, and to monitor the structure to limit the risks. It appears that there is no definitive and reliable solution to repair, on the long term, structures affected by DEF.

\section{References}

[1] Divet L, \& Randriambololana R. Delayed ettringite formation: the effect of temperature and basicity on the interaction of sulphate and C-S-H phase. Cement Concrete Res 1998; 28(3): 357-363.

[2] Tepponen P, \& Eriksson B-E. Damages in concrete railway sleepers in Finland. Nordic Concrete Res. 1987; 6: 199-209.

[3] Heinz D, Ludwig U, \& Rudiger I. Delayed ettringite formation in heat treated mortars and concretes. Betonwerk und Fertigteil-Tech. 1989; 55(11): 55-61.

[4] Vitouva L. Concrete sleepers in CSD tracks. International Symposium on Precast Concrete Railway Sleepers, Madrid, 1991, 253-264.

[5] Shayan A, \& Quick G-W. Microscopic feature of cracked and uncracked concrete railway sleepers. ACI Mater. 1992; 89(4): 348-361.

[6] Oberholster R-E, Maree H, Brand J-H-B. Cracked prestressed concrete railway sleepers: alkali-silica reaction or delayed ettringite formation. Proceedings of the 9th International Conference on Alkali-Silica Reaction or Delayed Formation in Concrete, CS104, vol. 2. London, 1992; 739-749.

[7] Mielenz R-C, Marusin S-L, Hime W-G, \& Jugovic Z-T. Investigation of prestressed concrete railway tie distress. Concrete Int. 1995; 17(12): 62-68.

[8] Sahu S, \& Thaulow N. Delayed ettringite formation in Swedish concrete railroad ties. Cement Concrete Res. 2004; 34(9): 1675-1681.

[9] Santos Silva A, Gonçalves A-F, Pipa M. Diagnosis and prognosis of Portuguese concrete 
railway sleepers degradation - a combination of ASR and DEF. Proceedings of the 13th International Conference on AAR in Concrete, vol. 89(4). Trondheim, Norway, 2008; 1240-1249.

[10] Collepardi M. Damage by delayed ettringite formation. Concrete Int. 1999; 21(1): 69-74.

[11] Hobbs D-W. Cracking of concrete attributed to delayed ettringite formation. Proceedings of the Eleventh Annual BCA/Concrete Society Conference on Higher Education and the Concrete Industry, paper 6, UMIST, Manchester, 2001; 51-60.

[12] Thomas M, Folliard K, Drimalas T, \& Ramlochan T. Diagnosing delayed ettringite formation in concrete structures. Cement Concrete Res. 2008; 38: 841-847.

[13] Ingham J. Delayed ettringite formation in concrete structures. Proceedings of the ICE Forensic Engineering 2012; 165(2): 59-62.

[14] Divet L, Guerrier F, \& Le Mestre G. Existe-t-il un risque de développement d'une réaction sulfatique d'origine endogène dans les pièces en béton de grande masse ? Le cas du pont d'Ondes. Bull. Laboratoires Ponts et Chaus. 1998; 213: 59-72.

[15] Godart B, Divet L. Lessons learned from structures damaged by delayed ettringite formation and the French prevention strategy. Proceedings of the Fifth international conference on Forensic Engineering, 15-17 April 2013, Institution of Civil Engineers, London.

[16] Divet $\mathrm{L}$. Les réactions sulfatiques internes au béton: contribution à l'étude des mécanismes de la formation différée de l'ettringite. Etudes et recherches des laboratoires des Ponts et Chaussées, no. 40. LCPC, OA, 2001; 227 pp.
[17] Godart B, Divet L. Recommandations pour la prévention des désordres dus à la réaction sulfatique interne. Techniques et Méthodes des laboratoires des ponts et chaussées, LCPC, 2007, (English version published by LCPC in 2009).

[18] Godart B, \& Divet L. DEF prevention in France and temperature control at early age. In CONCRACK 3 - RILEM-JCI International Workshop on Crack Control of Mass Concrete and Related Issues Concerning Early-Age of Concrete Structures, Toutlemonde F, Torrenti JM (eds) RILEM Publications: Paris, 2012.

[19] Martin R.-P., Bazin C., Toutlemonde F. Alkali aggregate reaction and delayed ettringite formation: common features and differences. Proceedings of the 14th International Conference on Alkali Aggregate Reaction, Austin, 21-25 May, 2012.

[20] Martin RP. Analyse sur Structures Modèles des Effets Mécaniques de la Réaction Sulfatique Interne du Béton. Thèse de doctorat (PhD Thesis, in French), Université Paris-Est, LCPC, Paris, France, 2010; 577 pp.

[21] Al Shamaa SM, Lavaud S, Divet L, Nahas G, \& Torrenti JM. Influence of relative humidity on delayed ettringite formation. Cement Concrete Compos. 2015; 58: 14-22.

[22] Kchakech B, Martin R-P, OmikrineMetalssi O, Renaud J-C, Baron L, Toutlemonde F. Experimental study of the influence of late heat treatment on the risk of expansion associated with delayed ettringite formation. Proceedings of the 15th International Conference on Alkali Aggregate Reaction, Paper 087, Sao Paulo, 4-8 July 2016.
[23] Godart B, \& Wood JGM. Appraising structures affected by the alkali-aggregate reaction. Construct. Mater. 2016; 169(3): 162-171.

[24] LCPC. Réaction Sulfatique Interne au béton - Essai d'expansion résiduelle sur carotte de béton extraite de l'ouvrage. Techniques et Méthodes des Laboratoires des Ponts et Chaussées, Méthode d'essai des LCPC, 67, 2009; $28 \mathrm{p}$.

[25] Li K, \& Coussy O. Concrete ASR degradation: from material modeling to structure assessment. Concrete Sci. Eng. 2002; 4: 34-46.

[26] Larive C. Apports combinés de l'expérimentation et de la modélisation à la compréhension de l'alcali-réaction et de ses effets mécaniques. Etudes et Recherches des Laboratoires des Ponts et Chaussées, LCPC, OA, 28, 1999.

[27] Brunetaud X. Etude de L'influence de Différents Paramètres et de Leurs Interactions Sur la Cinétique et L'amplitude de la Réaction Sulfatique Interne au Béton. Thèse de doctorat (PhD Thesis, in French), Ecole Centrale, Paris, 1996.

[28] Godart B, Omikrine-Métalssi O, Kchakech B, Lavaud S. The effects of delayed ettringite formation on the expansion of a massive bridge pier and a precast prestressed concrete beam of a bridge. Proceedings of the 15th International Conference on Alkali Aggregate Reaction, Sao Paulo, 4-8 July 2016.

[29] LCPC. Protection et réparation des ouvrages atteints de réactions de gonflement interne - recommandations provisoires. Techniques et Méthodes des Laboratoires des Ponts et Chaussées, Août, 2010, 141 pp. (In French) 